\title{
Effect of single-wall carbon nanotubes on bioconcentration and toxicity of perfluorooctane sulfonate in zebrafish (Danio rerio)
}

\author{
Yaxuan $\mathrm{Li}^{\mathrm{a}, \mathrm{b}}$, Bin Men ${ }^{\mathrm{a}, *}$, Yi He ${ }^{\mathrm{a}}$, Haiming $\mathrm{Xu}^{\mathrm{c}}$, Meiqi Liu ${ }^{\mathrm{a}}$, Dongsheng Wang ${ }^{\mathrm{a}, *}$ \\ a State Key Laboratory of Environmental Aquatic Chemistry, Research Centre for Eco-Environmental Science, Chinese Academy of Sciences, Beijing 100085, China \\ ${ }^{\mathrm{b}}$ University of Chinese Academy of Sciences, Beijing 100085, China

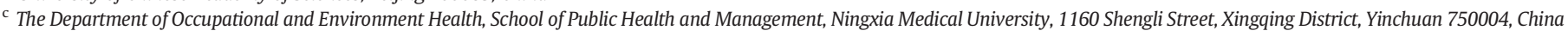

\section{H I G H L I G H T S}

- Co-exposure with SWCNT had an effect on the PFOS bioconcentration in zebrafish.

- The influence of PFOS on ROS, SOD, CAT and AChE were affected by co-exposure.

- The highest IBR were observed under co-exposure.

\section{G R A P H I C A L A B S T R A C T}

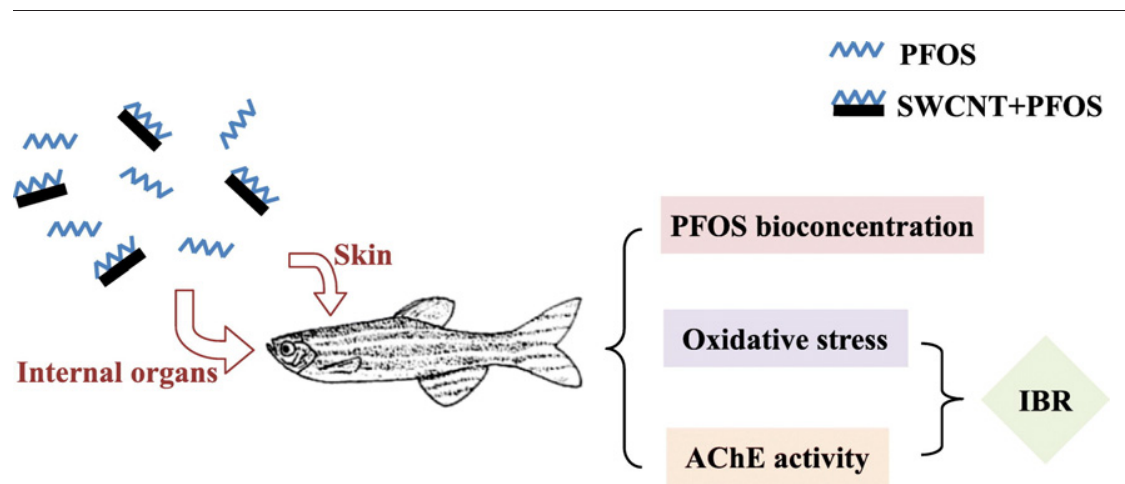

\section{A R T I C L E I N F O}

\section{Article history:}

Received 14 April 2017

Received in revised form 27 May 2017

Accepted 17 June 2017

Available online 27 July 2017

Editor: Henner Hollert

\section{Keywords:}

PFOS

SWCNT

Co-exposure

Bioconcentration

Oxidative stress

AChE

\begin{abstract}
A B S T R A C T
The wide application of nanoparticles will lead its release into the aquatic environment, which may alter the bioavailability and toxicity of other contaminants to aquatic organisms. This work aimed to study the effects of perfluorooctane sulfonate (PFOS), single-wall carbon nanotubes (SWCNT), and their mixture on PFOS accumulation, antioxidant defenses and acetylcholinesterase (AChE) activity in zebrafish. The fish was dissected after being exposed (24, 48, 72 and $96 \mathrm{~h}$ ) separately to PFOS, SWCNT and PFOS + SWCNT co-exposure. The bioaccumulation of PFOS in fish tissues (liver, intestines, gills and brain) decreased with increasing dosage of SWCNT, however, the opposite trend was observed in fish skin, which indicated that the bioavailability of PFOS changed by adsorption on SWCNT. Meanwhile, co-exposure induced more reactive oxygen species (ROS) than PFOS alone and enhanced the effect of PFOS on the superoxide dismutase (SOD), and catalase (CAT) and AChE activities. Furthermore, the integrated biomarker response (IBR) showed that co-exposure was the most stressful circumstance.
\end{abstract}

(c) 2017 Elsevier B.V. All rights reserved.

\section{Introduction}

Single wall carbon nanotubes (SWCNT) is seamless cylinders with graphene sheet wall, which is honeycomb lattice representing a single

\footnotetext{
* Corresponding authors.

E-mail addresses: binmen@rcees.ac.cn (B. Men), wgds@rcees.ac.cn (D. Wang).
}

atomic layer of crystalline graphite (Dresselhaus and Avouris, 2001). It has been widely applied in material strengthening, nanobiosensing, drug delivery systems, etc., because of its unique physicochemical, mechanical, and electrical properties (Klaine et al., 2008). In light of its rapid growth in research and commercialization, the worldwide use of SWCNT in large scale may lead inevitably release into aquatic environment and interactions with other chemical contaminants, resulting in 
complex toxic effects on organisms. Several studies have demonstrated that carbon nanotubes might have impacts on the bioavailability and toxicity of aquatic environmental contaminants. SWCNT could act as contaminants-carriers thus facilitate bioaccumulation of phenanthrene in Japanese medaka (Su et al., 2013). Carbon nanotubes increased the diuron toxicity through locally elevated exposure concentration in the proximity of algal cells (Schwab et al., 2013). SWCNT modified with lysophosphatidylcholine may interrupt the structure of membrane resulting in enhanced uptake and toxicity of copper in Daphnia magna (KT Kim et al., 2010). However, under some circumstances, nanoparticles could also reduce the bioaccumulation and toxicity of organic pollutants. For the high hydrophobic organochlorine compounds, the decrease of freely dissolved concentration by fullerene $\left(C_{60}\right)$ adsorption resulted in reduced bioaccumulation in medaka (Hu et al., 2010). In cultured cells, $17 \alpha$-Ethinylestradiol bioactivity could be inhibited by the stable adsorption of carboxyl-functionalized SWCNT (Song et al., 2014). Therefore, the adsorption property of nanoparticles played an important role in bioavailability and toxicity of pollutants in aquatic environment.

PFOS, as a persistent organic pollutant, has been widely used and the majority of PFOS is released into the aquatic environment during the production and application of non-stick cookware, food packaging, stain protectors, lubricants and fire-fighting foams (Paul et al., 2009). It has been confirmed that, PFOS is widely distributed on a global scale and can be persistent and bioaccumulative in various food chains (Giesy and Kannan, 2001). High concentration of PFOS has been detected in fish species ( $7760 \mathrm{ng} \mathrm{g}^{-1}$ wet weight) (Hoff et al., 2003), although PFOS concentrations is generally low in aquatic environment. Furthermore, the potential adverse impacts on aquatic organisms of PFOS, including development toxicity, hepatotoxicity, immune toxicity, neurotoxicity and endocrine disrupting, have been widely investigated (Du et al., 2009; Fang et al., 2012; Xia et al., 2015; Zhang et al., 2011; Zhang et al., 2014). Several studies have demonstrated that PFOS may induce oxidative stress, which causes the homeostasis of antioxidative systems being overwhelmed (Liu et al., 2007; Shi and Zhou, 2010). In addition, a recent study has indicated that PFOS may affect acetylcholinesterase (AChE) activity in aquatic animals (Jeong et al., 2016). And reduction of AChE activity would lead to accumulation of acetylcholine, thus altering the functioning of central nervous system (Dhull et al., 2013). Toxicity studies of co-exposure to PFOS and other material are increasing, as people realize that work on toxicity of PFOS alone cannot fully assess the risks of the contaminant. The endpoints of joint effects included bioaccumulation, malformation, mortality, metabolism, genes, etc. Carbonaceous materials could reduce the aqueous phase concentration and bioavailability of perfluorochemicals in Chironomus plumosus larvae due to the sorption (Xia et al., 2012). It was reported that the toxicity effect of oxidative stress biomarkers based on integrated biomarker response (IBR) analysis under PFOS and heavy metal coexposure was different from PFOS exposure alone, where the harmful effects were inhibited by cadmium (Qu et al., 2016) and zinc (Liu et al., 2016) in Limnodrilus hoffmeisteri but enhanced by copper in Carassius auratus (Feng et al., 2015). Co-exposure with Nano-ZnO increased the thyroid-disrupting effects (Du et al., 2016b) and DNA damage (Du et al., 2016a) of PFOS in zebrafish. However, there have been limited researches on toxicity of co-exposure to PFOS and SWCNT. Chen et al. (Chen et al., 2011) reported that SWCNT had high sorption capacity to PFOS. This interaction could influence the transport and toxicity effects of PFOS on aquatic organisms. Studying the relevant biological responses under co-exposure of PFOS and SWCNT is critical for the evaluation of the environmental risks in water.

In order to gain a deeper understanding on the joint toxicity effects of PFOS and SWCNT, zebrafish (Danio rerio), an attractive model vertebrate organism in toxicology, was employed as an in vivo model to investigate the physiological effects of PFOS co-exposed with SWCNT. To this end, PFOS bioconcentration distribution, oxidative stress (ROS, SOD and CAT) and AChE activity in fish tissue were examined.

\section{Materials and methods}

\subsection{Materials}

Perfluorooctane sulfonate potassium (PFOS, purity $\geq 98 \%$ ) was purchased from Sigma-Aldrich, and stock solution $(1.0 \mathrm{mg} / \mathrm{mL})$ of it was prepared in dimethyl sulfoxide (DMSO, purity $>99 \%$, Amresco, Solon, $\mathrm{OH})$ and stored at $4{ }^{\circ} \mathrm{C}$. $\left[1,2,3,4-{ }^{13} \mathrm{C}_{4}\right]$ perfluorooctane sulfonate (MPFOS) (purity $\geq 99 \%$ ) was purchased from Wellington Laboratories (Canada), and it was used as an internal standard. SWCNT was purchased from Beijing DK nano technology Co., LTD (purity $\geq 99.9 \%$, China). According to the manufacturer, SWCNT has a diameter of 1$2 \mathrm{~nm}$. SWCNT suspension was prepared by dispersing SWCNT in ultrapure water with sonication ( $300 \mathrm{~W}, 40 \mathrm{kHz}$ ) for 30 min before use. All other chemicals used in this study were of analytical grade and HPLC grade for PFOS analysis.

\subsection{Zebrafish}

A batch of fully mature zebrafish with mean body weight of $0.32 \pm$ $0.09 \mathrm{~g}$ and mean body length of $2.8 \pm 0.2 \mathrm{~cm}(\mathrm{n}=300)$ were purchased from China Zebrafish Resource Center. All fish were acclimatized in dechlorinated and aerated freshwater at least for 2 weeks at $\mathrm{pH} 7.0$ and $23 \pm 2{ }^{\circ} \mathrm{C}$. During acclimatization, fish were fed twice daily with commercial fish pellets and food residues were removed. The fish were starved for $24 \mathrm{~h}$ before experiment.

\subsection{Adsorption of PFOS on SWCNT}

Adsorption kinetics were determined in polypropylene (PP) cups with standard medium water which containing $294.0 \mathrm{mg} \mathrm{L}^{-1}$ $\mathrm{CaCl}_{2} \cdot 2 \mathrm{H}_{2} \mathrm{O}, 123.3 \mathrm{mg} \mathrm{L}^{-1} \mathrm{MgSO}_{4} \cdot 7 \mathrm{H}_{2} \mathrm{O}, 63.0 \mathrm{mg} \mathrm{L}^{-1} \mathrm{NaHCO}_{3}$ and $5.5 \mathrm{mg} \mathrm{L}^{-1} \mathrm{KCl}$ (ISO 7346-1 1996) in order to keep the same circumstances with exposure condition. PFOS stock solution was mixed with standard medium then SWCNT stock suspension was added. The adsorption solution contained $200 \mu \mathrm{g} \mathrm{L} \mathrm{L}^{-1}$ PFOS and SWCNT of different concentration $\left(5,10\right.$ and $\left.15 \mathrm{mg} \mathrm{L}^{-1}\right)$. Samples were drawn at desired time $(0,0.25,0.5,1,2,4,8,12$ and $24 \mathrm{~h})$ and then PFOS concentration was analyzed after centrifugation for $10 \mathrm{~min}$ at $14000 \mathrm{rpm}$ with a high-speed centrifuge. Control experiments were conducted using PFOS solution $\left(200 \mu \mathrm{g} \mathrm{L}^{-1}\right)$ without SWCNT. Samples were drawn at 0 and $24 \mathrm{~h}$ and then PFOS concentration was analyzed to assess the PFOS loss. And the result demonstrated that PFOS variation was negligible (97-102\% of initial concentration).

\subsection{Exposure assay}

The exposure solution was prepared $24 \mathrm{~h}$ before experiment to guarantee adsorption equilibrium. The control and exposure solution received $0.1 \%(\mathrm{v} / \mathrm{v})$ DMSO and the experiments were performed in quadruplicate. For PFOS bioacccumulation experiments, $200 \mu \mathrm{g} \mathrm{L}^{-1}$ PFOS was mixed with different amount of SWCNT $(0,5,10$, $\left.15 \mathrm{mg} \mathrm{L}^{-1}\right)$. Solution of PFOS $\left(200 \mu \mathrm{g} \mathrm{L}^{-1}\right)$, SWCNT $\left(15 \mathrm{mg} \mathrm{L}^{-1}\right)$ or PFOS + SWCNT ( $\left.200 \mu \mathrm{g} \mathrm{L}^{-1}+15 \mathrm{mg} \mathrm{L}^{-1}\right)$ were used for oxidative stress and AChE activity analysis. Zebrafish were exposed to $1 \mathrm{~L}$ solution for 4 days at $23 \pm 0.5{ }^{\circ} \mathrm{C}$ and photoperiod was set to $14 / 10 \mathrm{~h}$ of light/ dark in the incubator. Particle size distribution of SWCNT in exposure solution was measured using a laser diffraction instrument (Malvern Mastersizer 2000, Malvern, UK), and the result showed that, under each exposure condition with different SWCNT concentration, the main particle size was constant at $35 \mathrm{~nm}$ (D50) with a range from 2 to 158 nm (Fig. 1(b)).

One fish from each exposure tank was sampled at each predetermined interval during experiment (24, 48, 72 and 96 h). Sampled fish were anesthetized with ice water, then an incision was made along the ventral surface from the anus to the gills, and the liver, 

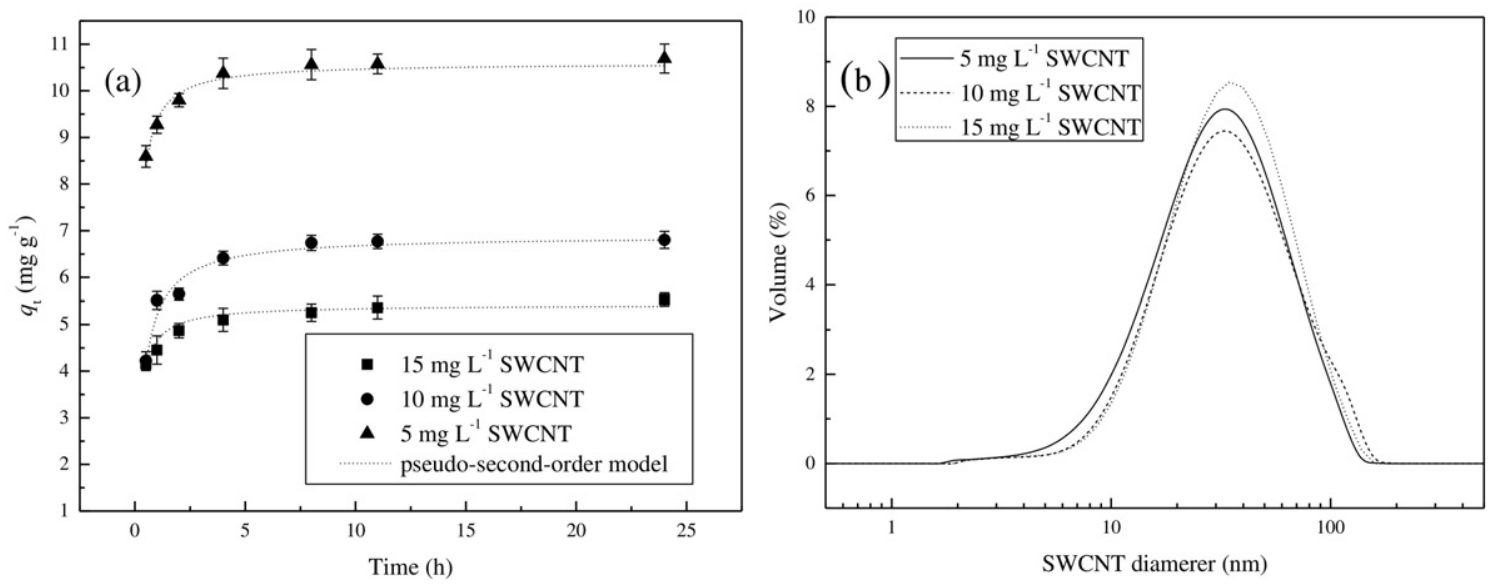

Fig. 1. (a) Adsorption kinetics of PFOS on SWCNT; (b) particle size distribution of SWCNT (PFOS $=200 \mu \mathrm{g} \mathrm{L}^{-1}$ ).

intestines, gills, brain and skin were removed and weighted. All the samples were stored in $-20^{\circ} \mathrm{C}$. PFOS in tissue samples was extracted in ion-pairing agent extracted method with some modification. Briefly, samples were homogenized with $200 \mu \mathrm{L}$ normal saline in $1.5 \mathrm{~mL}$ PP centrifuge tubes. $2 \mathrm{~mL}$ of $\mathrm{Na}_{2} \mathrm{CO}_{3}(0.25 \mathrm{M}), 1 \mathrm{~mL}$ of TBA ( $0.5 \mathrm{M}$, adjusted to $\mathrm{pH} 10$ ), and $50 \mu \mathrm{L}$ of MPFOS ( $5 \mathrm{ng}$ ) were added into each $15 \mathrm{~mL}$ PP centrifuge tube containing homogenate sample. The mixture was extracted with $5 \mathrm{~mL}$ of MTBE by shaking for $20 \mathrm{~min}$ at $25^{\circ} \mathrm{C}$, followed by centrifugation to isolate the organic phase. The MTBE supernatant was collected in a separate PP tube, and this extraction process was repeated twice more, combining the supernatants. The MTBE was allowed to evaporate under high-purity nitrogen gas before reconstituted in $1 \mathrm{~mL}$ methanol. The solution was vortex for $30 \mathrm{~s}$ then filtered through $0.22 \mu \mathrm{m}$ nylon filters into PP vials for analysis.

\subsection{Analysis of PFOS by UPLC-MS}

The PFOS analysis was performed using an ultra-performance liquid chromatography-tandem mass spectrometer (UPLC-MS) (ACQUITY UPLC-Quattro Premier XE, Waters Co, USA) equipped with an electrospray ion source (Micromass, Manchester, UK). Samples $(10 \mu \mathrm{L})$ were injected into a ACQUITY UPLC ${ }^{\circ}$ BEH C18 Column $(2.1 \times 50 \mathrm{~mm}$, $1.7 \mu \mathrm{m}$, Waters, USA) with ammonium acetate solution $(10 \mathrm{mM})$ and acetonitrile delivered at a flow rate of $0.2 \mathrm{~mL} \mathrm{~min}^{-1}$ as mobile phase. Desolvation temperature and gas flow was $350{ }^{\circ} \mathrm{C}$ and $600 \mathrm{~L} \mathrm{~h}^{-1}$. Other parameters for the instrument were optimized individually for PFOS and MPFOS and summarized in Table 1. Analysis data was performed using MassLynx software of the Micromass Quattro micro system (Waters, USA).

The determined limits of quantification (LOQs) $(\mathrm{S} / \mathrm{N}=3)$ for the PFOS and MPFOS by UPLC-MS were 0.09 and $0.07 \mu \mathrm{g} \mathrm{L}^{-1}$. Recovery rates of PFOS and MPFOS in biological samples were measured by adding $50 \mathrm{ng}$ of PFOS and $5 \mathrm{ng}$ of MPFOS into removed tissues of clean fish followed by ion-pairing agent extraction and UPLC-MS analysis. Experiments for each tissue were performed in sextuplicate. Recoveries of the PFOS and MPFOS from the tissue samples were between $85 \%$ and $102 \%$ and $93 \%$ and $109 \%$, respectively. The sample concentrations below the LOQs were set to zero, and all data were corrected according to the recovery indicators.

Table 1

List of target compounds analyzed and the MS parameters used.

\begin{tabular}{lllll}
\hline Analyte & Precursor ion & Product ion & Collision energy $(\mathrm{eV})$ & Cone voltage $(\mathrm{V})$ \\
\hline PFOS & 499.3 & 79.7 & 30 & 55 \\
MPFOS & 503.2 & 79.7 & 35 & 50 \\
\hline
\end{tabular}

\subsection{Oxidative stress}

Reactive oxygen species (ROS), superoxide dismutase (SOD), and catalase (CAT) were measured using the commercial test kits (Beyotime Biological Technology Co. Ltd., Shanghai, China) following the manufacturer's instructions. SOD activity was calculated using the following equation: SOD activity (inhibition rate\%) $=\left(\left[\left(\right.\right.\right.$ blank $_{1}-$ blank $\left._{3}\right)-$ $\left({\left.\left.\text { sample }- \text { blank }_{2}\right)\right] \text { / (blank }}_{1}-\right.$ blank $\left.\left._{3}\right)\right) \times 100$, and one U (unit) of SOD activity was identified as the quantity of enzyme that promoted $50 \%$ dismutation of the superoxide radical per $\mu$ protein. One $U$ of CAT activity was defined as the amount of enzyme that could decomposite $1.0 \mathrm{nmol}$ of $\mathrm{H}_{2} \mathrm{O}_{2}$ per minute per $\mu \mathrm{g}$ protein.

\subsection{AChE activity}

AChE activity in zebrafish tissue was determined following to the method in Xie et al. (Xie et al., 2013) with a little modification where $4 \mu \mathrm{L}$ tissue lysate was used for analysis. Absorbance of reaction mixture was determined at $410 \mathrm{~nm}$ with a multifunctional microplate spectrometer (TECAN Infinite F200, Männedorf, Switzerland) and the optical density (OD) was recorded at 2-min intervals in $16 \mathrm{~min}$ at $20^{\circ} \mathrm{C}$. $\mathrm{AChE}$ activity was calculated from the slope of the line that OD derived time, and one $U$ of AChE activity is defined as velocity (mOD per minute) per microgram of protein.

The protein concentration was determined with the Bradford method (Bradford, 1976). All enzyme activity data were expressed in \% of control.

\subsection{Integrated biomarker response}

The integrated biomarker response (IBR), an index obtained through computation of all biomarkers measured at a specific exposure condition, has been used for assessing potential biological effects in a multibiomarker approach (Beliaeff and Burgeot, 2002). Briefly, the calculation of IBR for all the biomarkers data (ROS, SOD, CAT and AChE) was as follows: standardization was using:

$\mathrm{Y}=(\mathrm{X}-\mathrm{m}) / \mathrm{s}$

Table 2

Kinetic parameters of the pseudo-second-order model for PFOS on SWCNT.

\begin{tabular}{llll}
\hline SWCNT dosage $\left(\mathrm{mg} \mathrm{L}^{-1}\right)$ & \multicolumn{3}{l}{ Parameters } \\
\cline { 2 - 4 } & $k\left(\mathrm{~g} \mathrm{mg}^{-1} \mathrm{~h}^{-1}\right)$ & $q_{e}\left(\mathrm{mg} \mathrm{g}^{-1}\right)$ & $R$ \\
\hline 5 & 0.72 & 10.60 & 0.95 \\
10 & 0.45 & 6.89 & 0.94 \\
15 & 1.12 & 5.42 & 0.94 \\
\hline
\end{tabular}



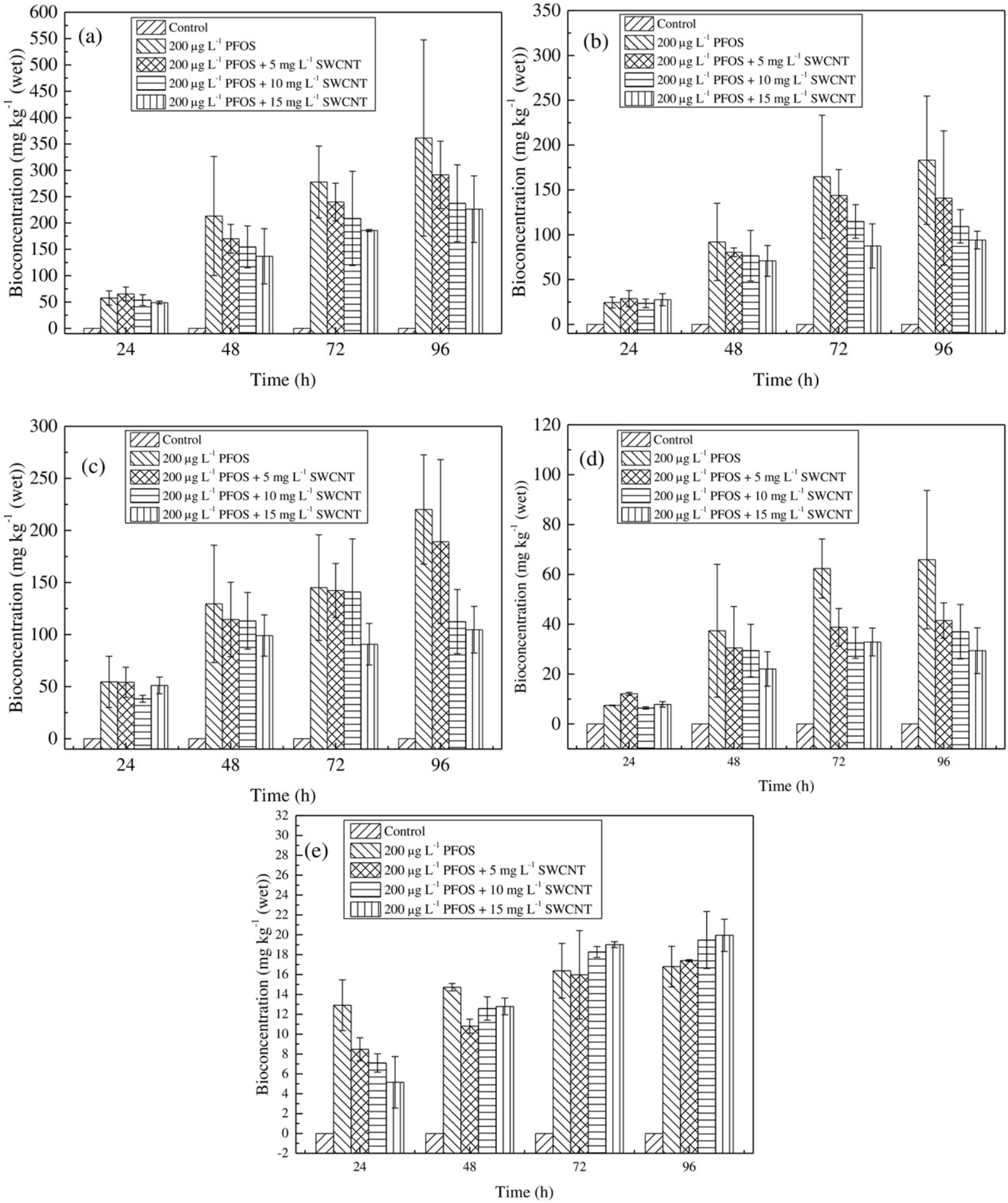

Fig. 2. PFOS bioconcentration in zebrafish tissues: (a) liver, (b) intestines, (c) gills, (d) brain, and (e) skin.

where $\mathrm{X}$ was the mean value for each biomarker of each exposure condition, $\mathrm{m}$ and $\mathrm{s}$ were the general mean and standard deviations of each biomarker for all exposure conditions.

Then $\mathrm{Z}$ was computed as $-\mathrm{Y}$ or $\mathrm{Y}$ in the case of a biological effect corresponding, respectively, to inhibition or activation. The minimum value (Min) of $Z$ for each biomarker was obtained and the score $S$ was computed as:

$\mathrm{S}=\mathrm{Z}+|\operatorname{Min}|$

where $|\mathrm{Min}|$ is the absolute value and $\mathrm{S} \geq 0$.
Table 3

$C_{W}$ of PFOS in each exposure solution.

\begin{tabular}{lll}
\hline Exposure condition & & $C_{W}$ of PFOS $\left(\mu \mathrm{g} \mathrm{L}^{-1}\right)$ \\
\hline PFOS $\left(\mu \mathrm{g} \mathrm{L}^{-1}\right)$ & SWCNT $\left(\mathrm{mg} \mathrm{L}^{-1}\right)$ & \\
\hline 200 & 0 & $205.33 \pm 7.24$ \\
200 & 5 & $161.50 \pm 6.18$ \\
200 & 10 & $127.12 \pm 4.97$ \\
200 & 15 & $87.47 \pm 3.82$ \\
\hline
\end{tabular}




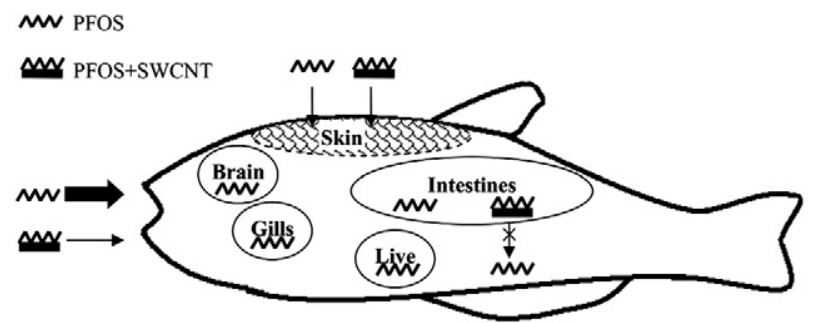

Fig. 3. Possible process of PFOS bioaccumulation in zebrafish. (The freely dissolved PFOS dominated PFOS accumulation in tissues, but SWCNT loaded PFOS could not be uptaken or release PFOS. The free and adsorbed PFOS both contributed to PFOS accumulation in skin.)

In the case of 4 biomarkers in this study, IBR for each exposure condition was calculated via the following formula:

$\mathrm{IBR}=\left(\mathrm{S}_{1} \times \mathrm{S}_{2}\right) / 2+\left(\mathrm{S}_{2} \times \mathrm{S}_{3}\right) / 2+\left(\mathrm{S}_{3} \times \mathrm{S}_{4}\right) / 2+\left(\mathrm{S}_{4} \times \mathrm{S}_{1}\right) / 2$

\subsection{Statistical analysis}

All results were presented as mean \pm standard deviation. The data were checked for normality of distribution using the Shapiro-Wilk test and for homogeneity of variance using the Levene test. The differences between the control and exposure groups were determined by Student's $t$-test or the Mann-Whitney test, depending on the distribution of the data and the homogeneity of the variances using SPSS 13.0.
Differences were considered statistically significant as $p$ value $<0.05$. Graphs were plotted with Origin 2016.

\section{Results and discussion}

\subsection{Adsorption of PFOS on SWCNT}

Fig. 1(a) showed the $24 \mathrm{~h}$ adsorption kinetics study that the adsorption equilibrium can be reached after $4 \mathrm{~h}$ and the free PFOS was stable in water.

The pseudo-second-order model was expressed as:

$\frac{t}{q_{t}}=\frac{1}{k q_{e}^{2}}+\frac{1}{q_{e}} t=\frac{1}{v_{0}}+\frac{1}{q_{e}} t$

$\mathrm{q}_{\mathrm{t}}=\frac{C_{0}-C_{t}}{m}$

where $q_{e}$ and $q_{t}\left(\mathrm{mg} \mathrm{g}^{-1}\right)$ are the amount of PFOS adsorbed on SWCNT at equilibrium and time $t(\mathrm{~h})$, respectively; $k$ is the rate constant $\left(\mathrm{g} \mathrm{mg}^{-1} \mathrm{~h}^{-1}\right) ; v_{0}$ is the initial sorption rate $\left(\mathrm{mg} \mathrm{g}^{-1} \mathrm{~h}^{-1}\right) ; C_{0}$ and $C_{t}$ are the PFOS solution concentration at initial and sampling time ( $\left.\mathrm{mg} \mathrm{L}^{-1}\right) ; m$ is the concentration of SWCNT $\left(\mathrm{g} \mathrm{L}^{-1}\right)$. The pseudosecond-order model can fit all adsorption data well as indicated by the high $R$ values (Table 2), suggesting the adsorption rate is controlled by chemical adsorption and adsorption capacity is proportional to the number of active sites of SWCNT. These results were in agreement with the research by Chen et al., where a high adsorption rate of PFOS by SWCNT was observed that only $2 \mathrm{~h}$ was required to reach
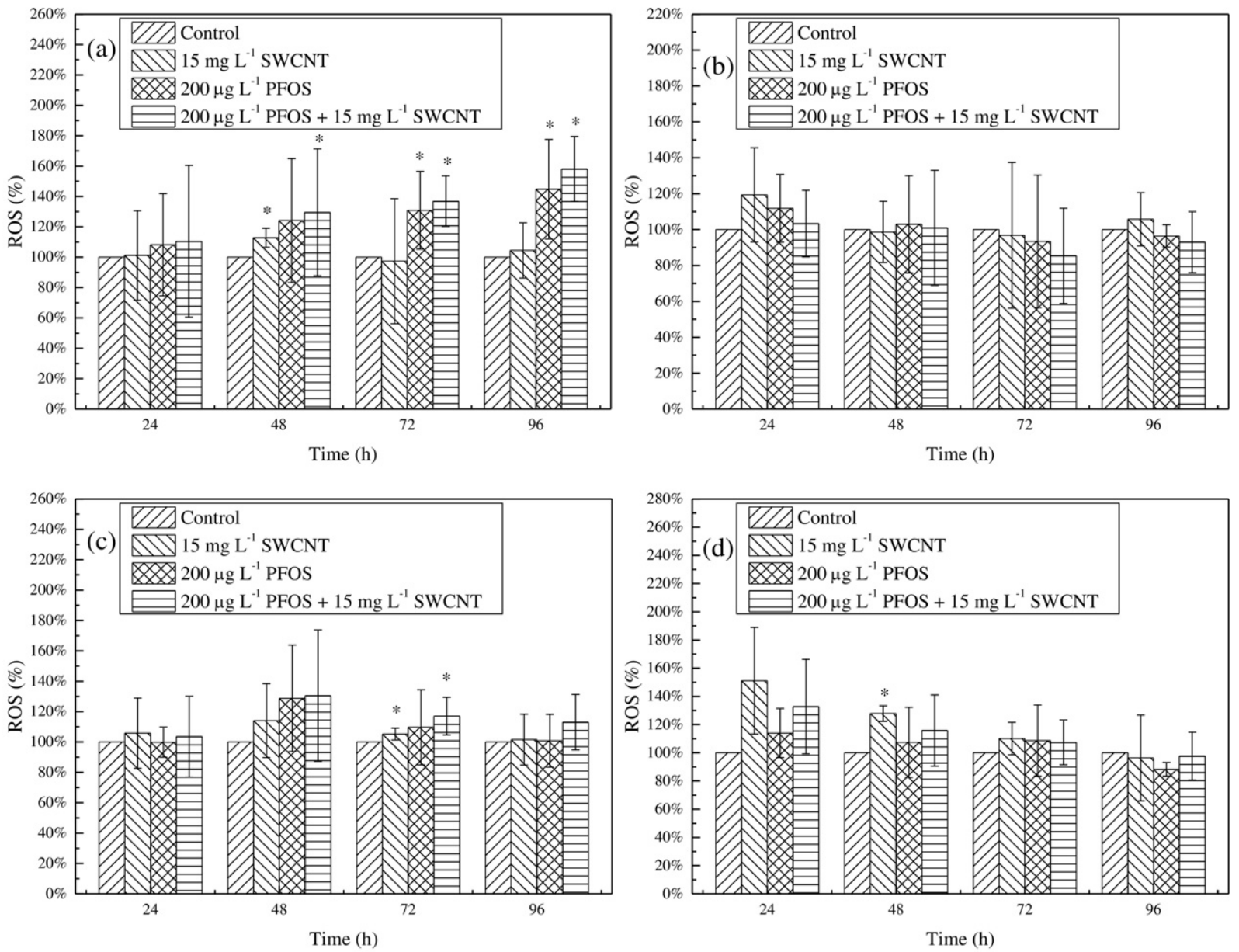

Fig. 4. ROS in zebrafish tissues: (a) liver, (b) intestines, (c) gills, (d) brain. 
equilibrium, as well as the fitness with pseudo-second-order model (Chen et al., 2011).

\subsection{The distribution of PFOS in tissues of zebrafish}

PFOS were not detected in the zebrafish samples of the control bioaccumulation experiments. In addition, variation of PFOS in exposure solution at day 4 was $<5 \%$. As shown in Fig. 2, levels of PFOS ( $\mathrm{mg} \mathrm{kg}^{-1}$, wet weight) in each tissue of fish exposed to PFOS increased with time. For each exposure condition during the whole experiment time, the max PFOS accumulation levels always appeared in liver. For example, the PFOS bioconcentration in liver at $96 \mathrm{~h}$ was 361.42, 291.44, 237.51 and $226.29 \mathrm{mg} \mathrm{kg}^{-1}$ for $200 \mu \mathrm{g} \mathrm{L}^{-1}$ PFOS, $200 \mu \mathrm{g} \mathrm{L}^{-1}$ PFOS $+5 \mathrm{mg} \mathrm{L}^{-1}$ SWCNT, $200 \mu \mathrm{g} \mathrm{L}^{-1}$ PFOS $+10 \mathrm{mg} \mathrm{L}^{-1}$ SWCNT and $200 \mu \mathrm{g} \mathrm{L}^{-1}$ PFOS $+15 \mathrm{mg} \mathrm{L}^{-1}$ SWCNT, respectively (Fig. 2(a)). The liver was the predominant accumulation tissue for PFOS, which was in agreement with the other research that the highest PFOS bioconcentration existed in the liver of rat after gavage exposure (Cui et al., 2009).

For internal tissue including liver, intestines, gills and brain (Fig. 2(a)-(d)), the PFOS bioaccumulation decreased with the increased dosage of SWCNT, and such trend is consistent at different exposure time. Usually, uptake of compound is related to its freely dissolved concentration than to its total concentration. The freely dissolved concentration of PFOS $\left(C_{W}\right)$ in each exposure solution was measured and the adsorption of PFOS to SWCNT resulted in a decline of $C_{W}$ with increasing SWCNT (Table 3 ). Such a decrease of $C_{W}$ may play the major role and leads to a reduced diffusive bioavailability of PFOS into zebrafish, which is in agreement with other work illustrating that $\mathrm{nC}_{60}$ decreased bioaccumulation of high hydrophobic organochlorine compounds in medaka (Hu et al., 2010), and hydrophobic organic contaminants (HOC) bioaccumulation might be reduce in polychaete through the highly sorption of HOC on SWCNT (Ferguson et al., 2008). Furthermore, SWCNT combining PFOS may not be uptaken into fish tissues or release PFOS, because appreciable uptake of SWCNT through the intestinal epithelium into tissues might not happen (Bisesi et al., 2014) and PFOS could be closely adsorbed on SWCNT (Deng et al., 2012).

Compared with internal organs, PFOS bioaccumulation on skin showed different pattern. In Fig. 2(e), it could be observed that PFOS bioconcentration in skin at $24 \mathrm{~h}$ decreased from 12.91 to $8.48,7.10$ and $5.16 \mathrm{mg} \mathrm{kg}^{-1}$ with SWCNT increased from 0 to 5,10 and $15 \mathrm{mg} \mathrm{L}^{-1}$. After $24 \mathrm{~h}$, PFOS bioaccumulation was enhanced by SWCNT gradually, and at $96 \mathrm{~h}$, it was 16.80,17.41, 19.48 and $19.95 \mathrm{mg} \mathrm{kg}^{-1}$ for $0,5,10$ and $15 \mathrm{mg} \mathrm{L}^{-1}$ of SWCNT. The skin of adult teleosts include cuticle or mucus layer, the epidermis and the dermis (Hawkes, 1974). Skin mucus can entrap and remove substances as mucus is continuously secreted and replaced (Nagashima et al., 2003). However, mucus can be shed or digested, thus toxic substances can move through and adhere to the epithelium surface or penetrate a mucus blanket (Cone, 2009). For example, multiwalled carbon nanotubes could accumulation on skin of zebrafish but little internalized in blood and muscle (Maes et al., 2014). In this study, at the beginning of exposure, freely dissolved fraction of PFOS contributed the most in bioaccumulation on skin when mucus of zebrafish functioned well. Then the mucus might be disrupted gradually, and SWCNT loading PFOS could contact and adhere to the epithelial surfaces, resulting in enhanced PFOS bioconcentration.
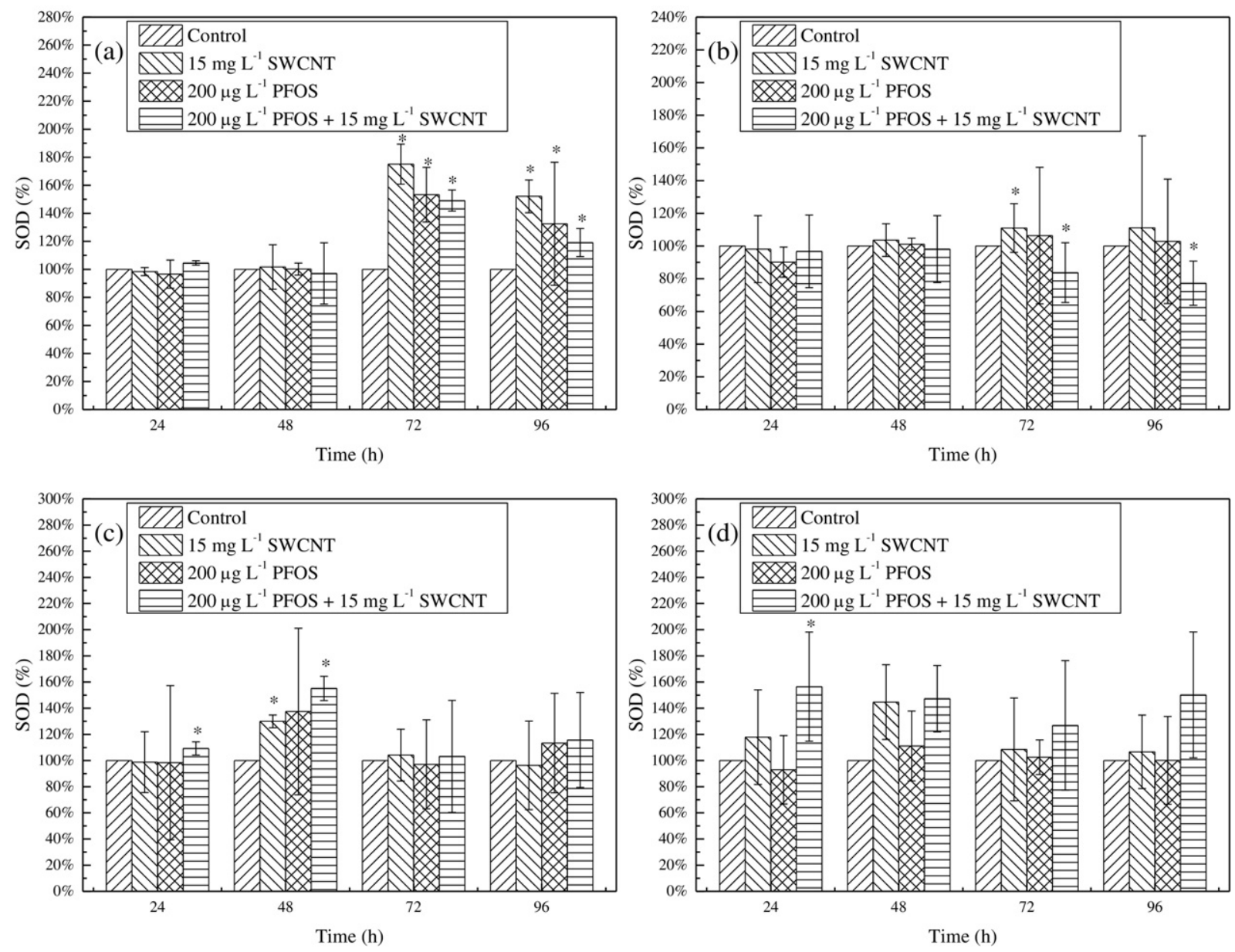

Fig. 5. SOD in zebrafish tissues: (a) liver, (b) intestines, (c) gills, (d) brain. 
The mechanism of the variation in PFOS bioaccumulation caused by SWCNT need more experimental research. However, the present study shows that PFOS alone is more bioavailable for inner tissue uptake, while the presence of SWCNT is in favor of PFOS bioaccumulation on surface skin, which may be due to the adsorption behavior of SWCNT (possible PFOS bioaccumulation process was shown in Fig. 3).

\subsection{Oxidative stress}

Many contaminants could produce ROS in animal, and the imbalance between ROS and antioxidant defenses would induce oxidative stress. It could be observed in Fig. 4(a) that under SWCNT exposure ROS increased significantly at $48 \mathrm{~h}$, and under PFOS and co-exposure at 72, $96 \mathrm{~h}$ and 48, 72, $96 \mathrm{~h}$, respectively, in liver. However, ROS levels under each exposure condition were not significantly different from control and in intestines (Fig. 4(b)) during experiment. In gills (Fig. 4(c)), the ROS showed significant change under SWCNT and co-exposure at $72 \mathrm{~h}$, while in brain (Fig. 4(d)) under SWCNT at $48 \mathrm{~h}$.

Many researches have demonstrated that PFOS could increase ROS production in vitro and in vivo, which might further cause cells apoptosis (Lee et al., 2012) or DNA damage (Xu et al., 2013). Co-exposure enhanced the increasing effect of PFOS on ROS in liver but not statistically significantly. However, synergy between SWCNT and PFOS for ROS stimulation might exist when taking into consideration that coexposure decreased the PFOS bioconcentration. This synergy may be because that SWCNT could induce ROS generation either (Pulskamp et al., 2007).
SOD and CAT function together as the first line to convert ROS production to harmless metabolites. Hydrogen peroxide generates through SOD catalyzing superoxide radicals then degrades into water and molecular oxygen via CAT which is a family of enzymes mainly locating in peroxisomes (Modesto and Martinez, 2010). Antioxidant enzymes could be induced to allow organisms dealing with stress resulting from unsafe exposure (Cossu et al., 1997), but excess of oxidants might inactivate enzymes involved in the antioxidant defense process (Modesto and Martinez, 2010).

SOD activity could be induced under mild external pressure but inhibited by severe injury under toxicity exposure (Liesivuori and Savolainen, 1991). It could be observed in liver (Fig. 5(a)) that PFOS induced SOD activity, while co-exposure weakened the effect after 72 and $96 \mathrm{~h}$, and even inhibited the activity in intestines (Fig. 5(b)). Moreover, in gill (Fig. 5(c)), co-exposure induced the significant increase of SOD activity at $24 \mathrm{~h}$ and $48 \mathrm{~h}$, and in brain (Fig. 5(d)) at $24 \mathrm{~h}$, while SOD activity maintained unchanged under PFOS alone. These results indicated that whether inhibition or induction, co-exposure induced more severe response of SOD activity in zebrafish.

It could be observed that PFOS induced CAT activity or had no significant effect in each tissue (Fig. 6). The CAT stimulation effect of PFOS in zebrafish is consistent with the study of Liu et al. (Liu et al., 2007), in which CAT increase in hepatocytes of freshwater tilapia was observed after treatment with PFOS. In intestines, gills and brain (Fig. 6(b-d)), at $24 \mathrm{~h}$, the enhanced CAT activity increased more in co-exposure condition than in PFOS, while co-exposure weakened the stimulation in liver (Fig. 6(a)). The activity of CAT can be induced by the increase of pro-oxidants as an adaptive response (Alves et al., 2002). However,
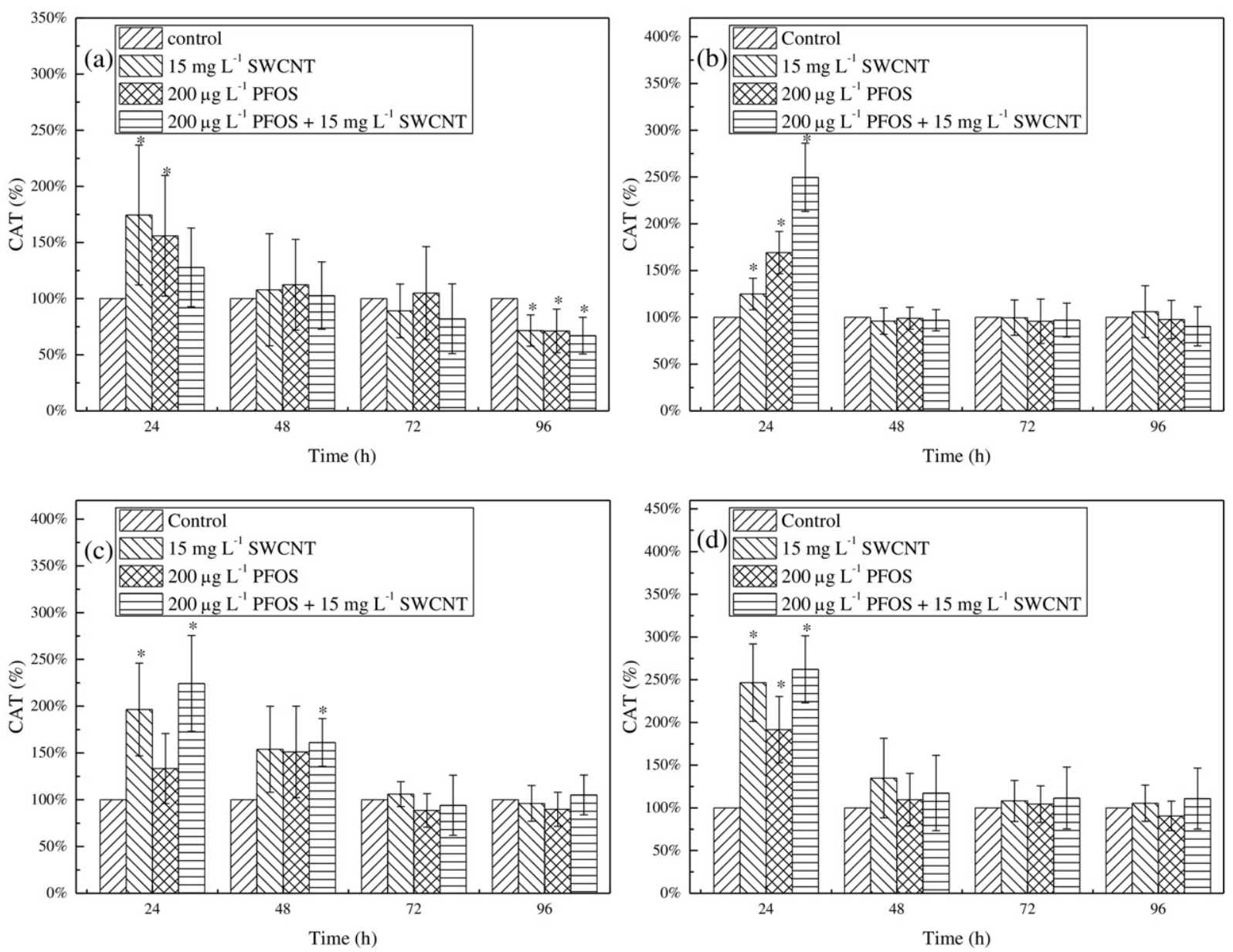

Fig. 6. CAT in zebrafish tissues: (a) liver, (b) intestines, (c) gills, (d) brain. 
CAT could be inactivated by interaction with excess superoxide anion (Bagnyukova et al., 2006), which could explain the maintenance $(24 \mathrm{~h})$ and inhibition $(96 \mathrm{~h})$ of CAT in liver under co-exposure (Fig. 5(a)). Similar to SOD, co-exposure had impact that is more serious on CAT activity.

Tissues in fish showed different enzymatic activity responses to defend oxidative stress (Ahmad et al., 2000). Furthermore, the activity of antioxidant defenses may be affected depending on the exposure condition, the susceptibility of the exposed species and other factors, therefore the literature reports highly variable results about the enzymes activities. In this study, the ROS induction and activity of antioxidant enzyme fluctuated with time, and tissues showed injury and recovery in different levels, which could be attributed to the adaptation mechanism of organism (Oruç and Usta, 2007). Moreover, these results indicate that co-exposure may enhance the effects of PFOS on ROS, SOD and CAT. This may be because SWCNT could affect the antioxidant system either (Manna et al., 2005).

\subsection{Acetylcholinesterase (AChE)}

As AChE is responsible for acetylcholine-mediated neurotransmission, its activity is considered as an indicator for neurological function disturbance. As shown in Fig. 7, AChE activity fluctuated in all of the exposure periods. During the continuous exposure, significantly decreased activities were detected in liver, intestines and gills under each exposure condition at different time (Fig. 7(a-c)). However, SWCNT and PFOS alone had no effect on AChE activity in brain, while increased AChE activity was observed only at $48 \mathrm{~h}$ under co-exposure
(Fig. 7(d)). It had been demonstrated that perfluorononanoic acid (PFOA) could inhibit AChE activity in vitro (Mulkiewicz et al., 2007), and PFOS exposure had no influence on AChE activity in the brain of common carp (W-K Kim et al., 2010). In this study, regardless of the AChE activity being inhibited or maintained, coexposure might induce more severe effect compared to being exposed to PFOS alone, considering decrease of PFOS bioconcentration caused by co-exposure.

\subsection{Integrated biomarker response (IBR)}

The usefulness of IBR was previously demonstrated in field studies, regardless of the considerable variability in the biomarker sets, contamination profiles and species (Broeg and Lehtonen, 2006; Damiens et al., 2007; Oliveira et al., 2009). As the IBR could be considered as a general description of the "health status" (Leiniö and Lehtonen, 2005), higher IBR suggested more stressful circumstance. According to the IBR index showed in Fig. 8, the control group showed the less extent and area, and the most affected exposure group was the co-exposure one. The largest IBR values appeared at $24 \mathrm{~h}$ that was 29.26, 17.29, 8.34 and 9.59 for liver, intestines, gills and brain respectively. In the present study, IBR index signaled co-exposure as the most stressful condition, which was in coordination with the results that co-exposure induced more severe responses of oxidative stress and AChE activity by PFOS exposure in zebrafish. Furthermore, the index in tissue decreased after $24 \mathrm{~h}$, which might indicate that zebrafish could recover from the polluted environment.
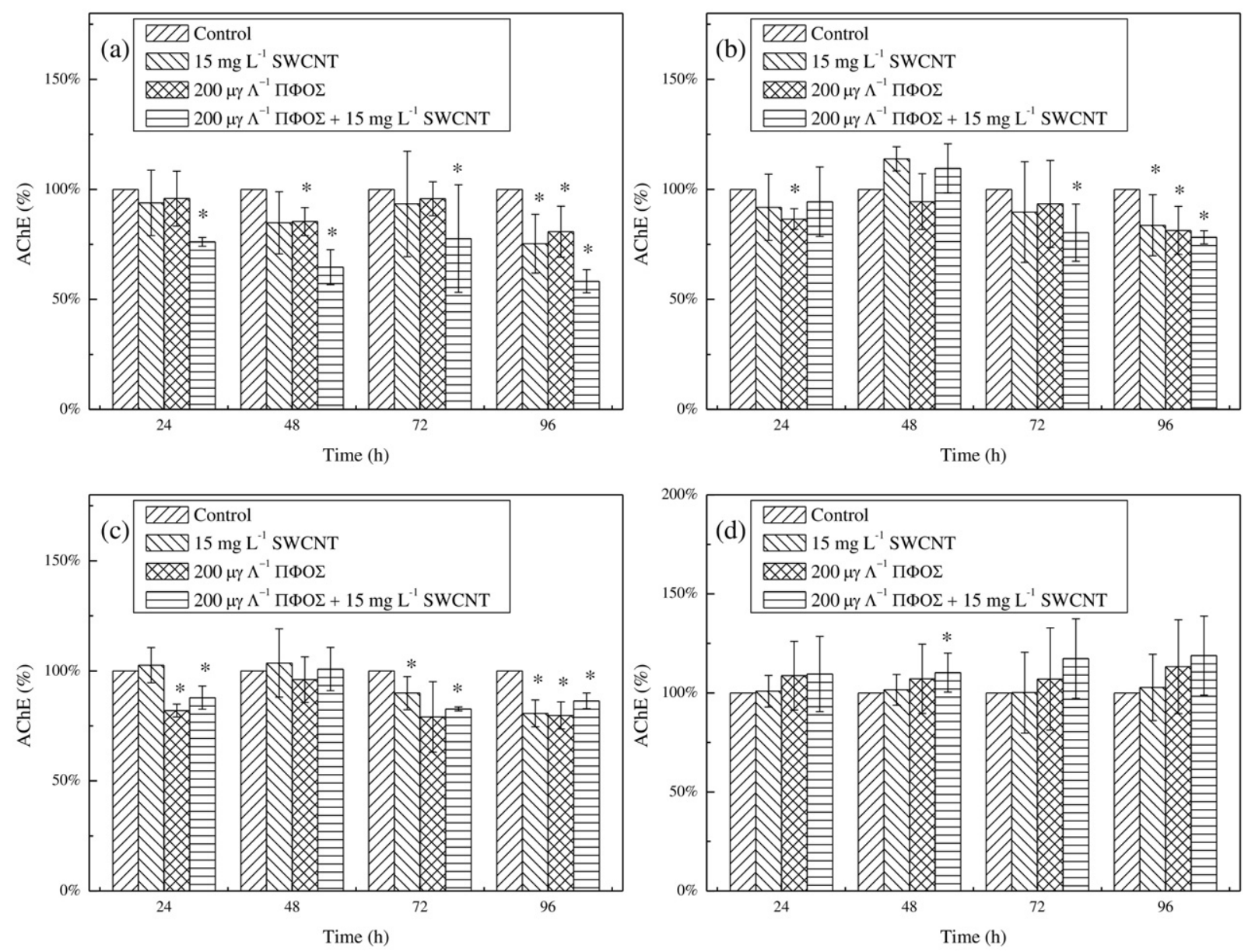

Fig. 7. AChE activity in zebrafish tissues: (a) liver, (b) intestines, (c) gills, (d) brain. 

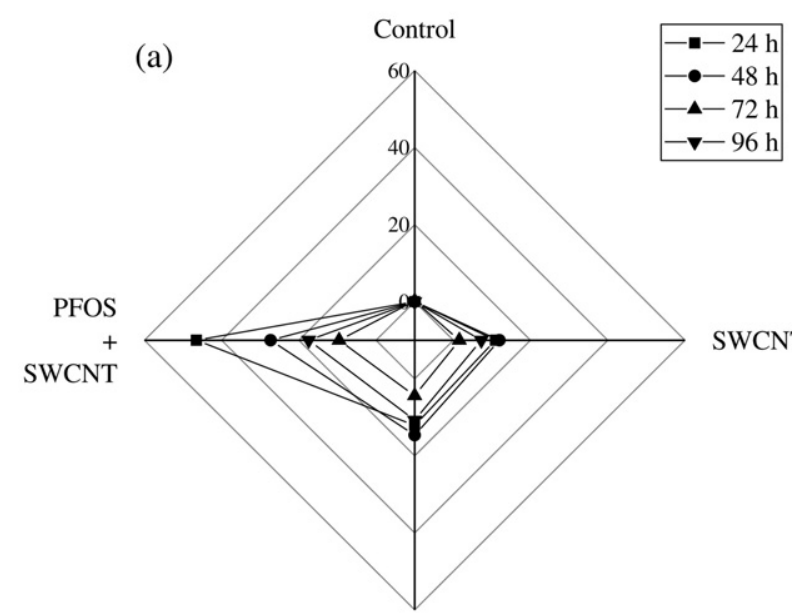

PFOS

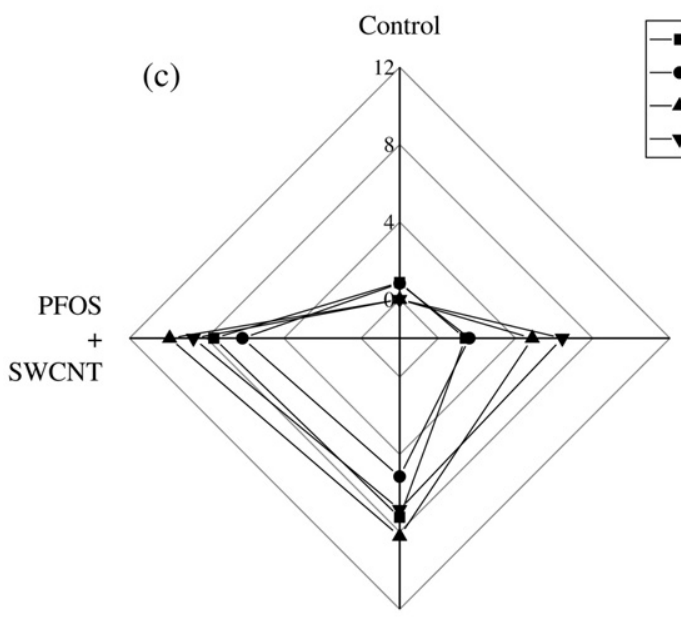

PFOS

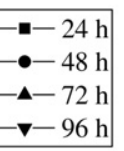

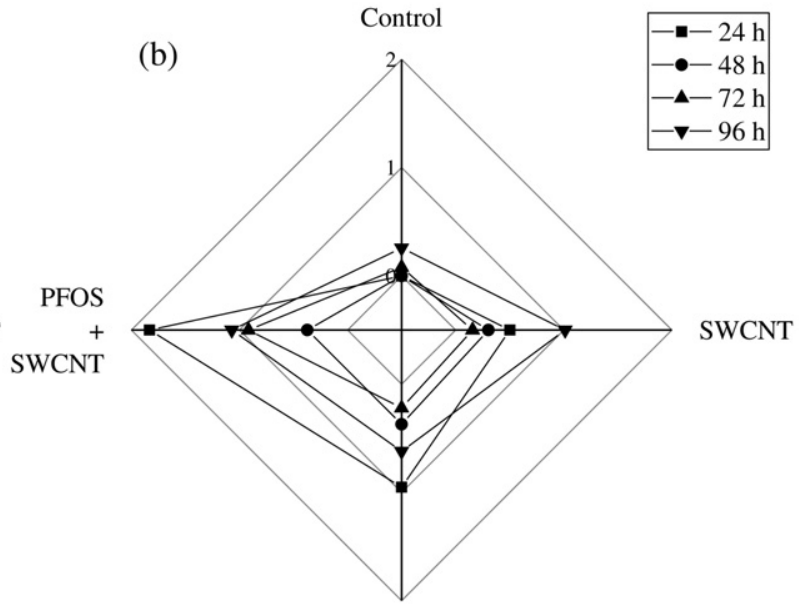

PFOS

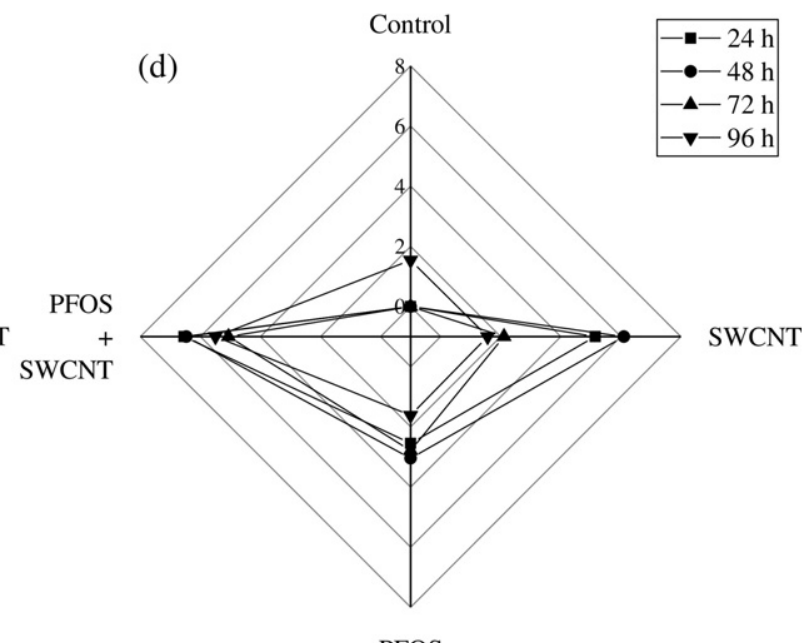

Fig. 8. IBR in zebrafish tissues: (a) liver, (b) intestines, (c) gills, (d) brain.

\section{Conclusion}

In summary, co-exposure would affect the PFOS accumulation, responses of antioxidant system, and the activity of AChE in zebrafish. PFOS in water could be adsorbed by SWCNT, which reduced the bioconcentration in zebrafish tissue and enhanced that in skin. Coexposure enhanced the injury effect of PFOS on ROS, SOD, CAT and AChE activity. IBR also showed that co-exposure was the most stressful exposure condition. Hence, this study may improve the understanding of complex impacts from SWCNT on the toxicity of PFOS in the aquatic environment. However, more research is required to address that SWCNT and PFOS are additive, synergistic, or antagonistic. It is necessary to take the potential interactions of nanoparticles with other contaminants into consideration during environmental risk assessments.

\section{Acknowledgements}

This study was sponsored by the National Natural Scientific Foundation of China (21677156, 41201498, 51290282), the National Water Pollution Control and Treatment Science and Technology Major Project (2015ZX07205-003), and the special fund from the State Key Joint Laboratory of Environment Simulation and Pollution Control (Research Center for Eco-environmental Sciences, Chinese Academy of Sciences) (Project No. 16Z02ESPCR).

\section{References}

Ahmad, I., Hamid, T., Fatima, M., Chand, H.S., Jain, S.K., Athar, M., et al., 2000. Induction of hepatic antioxidants in freshwater catfish (Channa punctatus Bloch) is a biomarker of paper mill effluent exposure. Biochim. Biophys. Acta Gen. Subj. 1523, 37-48.

Alves, S.R.C., Severino, PcC, Ibbotson, D.P., da Silva, A.Z., Lopes, F.R.A.S., Sáenz, L.A., et al., 2002. Effects of furadan in the brown mussel Perna perna and in the mangrove oyster Crassostrea rhizophorae. Mar. Environ. Res. 54, 241-245.

Bagnyukova, T.V., Chahrak, O.I., Lushchak, V.I., 2006. Coordinated response of goldfish antioxidant defenses to environmental stress. Aquat. Toxicol. 78, 325-331.

Beliaeff, B., Burgeot, T., 2002. Integrated biomarker response: a useful tool for ecological risk assessment. Environ. Toxicol. Chem. 21, 1316-1322.

Bisesi Jr., J.H., Merten, J., Liu, K., Parks, A.N., Afrooz, A.R., Glenn, J.B., et al., 2014. Tracking and quantification of single-walled carbon nanotubes in fish using near infrared fluorescence. Environ. Sci. Technol. 48, 1973-1983.

Bradford, M.M., 1976. A rapid and sensitive method for the quantitation of microgram quantities of protein utilizing the principle of protein-dye binding. Anal. Biochem. $72,248-254$.

Broeg, K., Lehtonen, K.K., 2006. Indices for the assessment of environmental pollution of the Baltic Sea coasts: integrated assessment of a multi-biomarker approach. Mar. Pollut. Bull. 53, 508-522.

Chen, X., Xia, X., Wang, X., Qiao, J., Chen, H., 2011. A comparative study on sorption of perfluorooctane sulfonate (PFOS) by chars, ash and carbon nanotubes. Chemosphere $83,1313-1319$.

Cone, R.A., 2009. Barrier properties of mucus. Adv. Drug Deliv. Rev. 61, 75-85.

Cossu, C., Doyotte, A., Jacquin, M.C., Babut, M., Exinger, A., Vasseur, P., 1997. Glutathione reductase, selenium-dependent glutathione peroxidase, glutathione levels, and lipid peroxidation in freshwater bivalves, Unio tumidus, as biomarkers of aquatic contamination in field studies. Ecotoxicol. Environ. Saf. 38, 122-131.

Cui, L., Zhou, Q.F., Liao, C.Y., Fu, J.J., Jiang, G.B., 2009. Studies on the toxicological effects of PFOA and PFOS on rats using histological observation and chemical analysis. Arch. Environ. Contam. Toxicol. 56, 338-349. 
Damiens, G., Gnassia-Barelli, M., Loquès, F., Roméo, M., Salbert, V., 2007. Integrated biomarker response index as a useful tool for environmental assessment evaluated using transplanted mussels. Chemosphere 66, 574-583.

Deng, S., Zhang, Q., Nie, Y., Wei, H., Wang, B., Huang, J., et al., 2012. Sorption mechanisms of perfluorinated compounds on carbon nanotubes. Environ. Pollut. 168, 138-144.

Dhull, V., Gahlaut, A., Dilbaghi, N., Hooda, V., 2013. Acetylcholinesterase biosensors for electrochemical detection of organophosphorus compounds: a review. Biochem. Res. Int. 2013, 18.

Dresselhaus, M.S., Avouris, P., 2001. Introduction to carbon materials research. In: Dresselhaus, M.S., Dresselhaus, G., Avouris, P. (Eds.), Carbon Nanotubes: Synthesis, Structure, Properties, and Applications. Springer, Berlin Heidelberg, Berlin, Heidelberg, pp. 1-9.

Du, Y., Shi, X., Liu, C., Yu, K., Zhou, B., 2009. Chronic effects of water-borne PFOS exposure on growth, survival and hepatotoxicity in zebrafish: a partial life-cycle test. Chemosphere 74, 723-729.

Du, J., Wang, S., You, H., Jiang, R., Zhuang, C., Zhang, X., 2016a. Developmental toxicity and DNA damage to zebrafish induced by perfluorooctane sulfonate in the presence of ZnO nanoparticles. Environ. Toxicol. 31, 360-371.

Du, J., Wang, S., You, H., Liu, Z., 2016b. Effects of ZnO nanoparticles on perfluorooctane sulfonate induced thyroid-disrupting on zebrafish larvae. J. Environ. Sci. 47, 153-164.

Fang, C., Wu, X., Huang, Q., Liao, Y., Liu, L., Qiu, L., et al., 2012. PFOS elicits transcriptional responses of the ER, AHR and PPAR pathways in Oryzias melastigma in a stage-specific manner. Aquat. Toxicol. 106-107, 9-19.

Feng, M., He, Q., Meng, L., Zhang, X., Sun, P., Wang, Z., 2015. Evaluation of single and joint toxicity of perfluorooctane sulfonate, perfluorooctanoic acid, and copper to Carassius auratus using oxidative stress biomarkers. Aquat. Toxicol. 161, 108-116.

Ferguson, P.L., Chandler, G.T., Templeton, R.C., DeMarco, A., Scrivens, W.A., Englehart, B.A. 2008. Influence of sediment - amendment with single-walled carbon nanotubes and diesel soot on bioaccumulation of hydrophobic organic contaminants by benthic invertebrates. Environ. Sci. Technol. 42, 3879-3885.

Giesy, J.P., Kannan, K., 2001. Global distribution of perfluorooctane sulfonate in wildlife. Environ. Sci. Technol. 35, 1339-1342.

Hawkes, J.W., 1974. The structure of fish skin. Cell Tissue Res. 149, 159-172.

Hoff, P.T., Van de Vijver, K., Van Dongen, W., Esmans, E.L., Blust, R., De Coen, W.M., 2003. Perfluorooctane sulfonic acid in bib (Trisopterus luscus) and plaice (Pleuronectes platessa) from the Western Scheldt and the Belgian North Sea: distribution and biochemical effects. Environ. Toxicol. Chem. 22, 608-614.

Hu, X., Liu, J., Zhou, Q., Lu, S., Liu, R., Cui, L., et al., 2010. Bioavailability of organochlorine compounds in aqueous suspensions of fullerene: evaluated with medaka (Oryzias latipes) and negligible depletion solid-phase microextraction. Chemosphere 80 693-700.

Jeong, T.-Y., Yuk, M.-S., Jeon, J., Kim, S.D., 2016. Multigenerational effect of perfluorooctane sulfonate (PFOS) on the individual fitness and population growth of Daphnia magna. Sci. Total Environ. 569-570, 1553-1560.

Kim, K.T., Klaine, S.J., Lin, S., Ke, P.C., Kim, S.D., 2010a. Acute toxicity of a mixture of copper and single-walled carbon nanotubes to Daphnia magna. Environ. Toxicol. Chem. 29, $122-126$.

Kim, W.-K., Lee, S.-K., Jung, J., 2010b. Integrated assessment of biomarker responses in common carp (Cyprinus carpio) exposed to perfluorinated organic compounds. J. Hazard. Mater. 180, 395-400.

Klaine, S.J., Alvarez, P.J.J., Batley, G.E., Fernandes, T.F., Handy, R.D., Lyon, D.Y., et al., 2008. Nanomaterials in the environment: behavior, fate, bioavailability, and effects. Environ. Toxicol. Chem. 27, 1825-1851.

Lee, H.-G., Lee, Y.J., Yang, J.-H., 2012. Perfluorooctane sulfonate induces apoptosis of cerebellar granule cells via a ROS-dependent protein kinase C signaling pathway. NeuroToxicology 33, 314-320.

Leiniö, S., Lehtonen, K.K., 2005. Seasonal variability in biomarkers in the bivalves Mytilus edulis and Macoma balthica from the northern Baltic Sea. Comp. Biochem. Physiol. C: Toxicol. Pharmacol. 140, 408-421.

Liesivuori, J., Savolainen, A.H., 1991. Methanol and formic acid toxicity: biochemical mechanisms. Pharmacol. Toxicol. 69, 157-163.

Liu, C., Yu, K., Shi, X., Wang, J., Lam, P., Wu, R., et al., 2007. Induction of oxidative stress and apoptosis by PFOS and PFOA in primary cultured hepatocytes of freshwater tilapia (Oreochromis niloticus). Aquat. Toxicol. 82, 135-143.
Liu, J., Qu, R., Yan, L., Wang, L., Wang, Z., 2016. Evaluation of single and joint toxicity of perfluorooctane sulfonate and zinc to Limnodrilus hoffmeisteri: acute toxicity, bioaccumulation and oxidative stress. J. Hazard. Mater. 301, 342-349.

Maes, H.M., Stibany, F., Giefers, S., Daniels, B., Deutschmann, B., Baumgartner, W., et al. 2014. Accumulation and distribution of multiwalled carbon nanotubes in zebrafish (Danio rerio). Environ. Sci. Technol. 48, 12256-12264.

Manna, S.K., Sarkar, S., Barr, J., Wise, K., Barrera, E.V., Jejelowo, O., et al., 2005. Singlewalled carbon nanotube induces oxidative stress and activates nuclear transcription factor-kB in human keratinocytes. Nano Lett. 5, 1676-1684.

Modesto, K.A., Martinez, C.B., 2010. Roundup causes oxidative stress in liver and inhibits acetylcholinesterase in muscle and brain of the fish Prochilodus lineatus. Chemosphere 78, 294-299.

Mulkiewicz, E., Jastorff, B., Składanowski, A.C., Kleszczyński, K., Stepnowski, P., 2007. Evaluation of the acute toxicity of perfluorinated carboxylic acids using eukaryotic cel lines, bacteria and enzymatic assays. Environ. Toxicol. Pharmacol. 23, 279-285.

Nagashima, Y., Kikuchi, N., Shimakura, K., Shiomi, K., 2003. Purification and characterization of an antibacterial protein in the skin secretion of rockfish Sebastes schlegeli. Comp. Biochem. and Physiol. C: Toxicol. Pharmacol. 136, 63-71.

Oliveira, M., Maria, V.L., Ahmad, I., Serafim, A., Bebianno, M.J., Pacheco, M., et al., 2009. Contamination assessment of a coastal lagoon (Ria de Aveiro, Portugal) using defence and damage biochemical indicators in gill of Liza aurata - an integrated biomarker approach. Environ. Pollut. 157, 959-967.

Oruç, E.Ö., Usta, D., 2007. Evaluation of oxidative stress responses and neurotoxicity potential of diazinon in different tissues of Cyprinus carpio. Environ. Toxicol. Pharmacol. 23, 48-55.

Paul, A.G., Jones, K.C., Sweetman, A.J., 2009. A first global production, emission, and environmental inventory for Perfluorooctane sulfonate. Environ. Sci. Technol. 43, 386-392.

Pulskamp, K., Diabaté, S., Krug, H.F., 2007. Carbon nanotubes show no sign of acute toxicity but induce intracellular reactive oxygen species in dependence on contaminants. Toxicol. Lett. 168, 58-74.

Qu, R., Liu, J., Wang, L., Wang, Z., 2016. The toxic effect and bioaccumulation in aquatic oligochaete Limnodrilus hoffmeisteri after combined exposure to cadmium and perfluorooctane sulfonate at different $\mathrm{pH}$ values. Chemosphere 152, 496-502.

Schwab, F., Bucheli, T.D., Camenzuli, L., Magrez, A., Knauer, K., Sigg, L., et al., 2013. Diuron sorbed to carbon nanotubes exhibits enhanced toxicity to Chlorella vulgaris. Environ. Sci. Technol. 47, 7012-7019.

Shi, X., Zhou, B., 2010. The role of Nrf2 and MAPK pathways in PFOS-induced oxidative stress in zebrafish embryos. Toxicol. Sci.

Song, M., Wang, F., Zeng, L., Yin, J., Wang, H., Jiang, G., 2014. Co-exposure of carboxylfunctionalized single-walled carbon nanotubes and 17alpha-ethinylestradiol in cultured cells: effects on bioactivity and cytotoxicity. Environ. Sci. Technol. 48 13978-13984.

Su, Y., Yan, X., Pu, Y., Xiao, F., Wang, D., Yang, M., 2013. Risks of single-walled carbon nanotubes acting as contaminants-carriers: potential release of phenanthrene in Japanese medaka (Oryzias latipes). Environ. Sci. Technol. 47, 4704-4710.

Xia, X., Chen, X., Zhao, X., Chen, H., Shen, M., 2012. Effects of carbon nanotubes, chars, and ash on bioaccumulation of perfluorochemicals by Chironomus plumosus larvae in sediment. Environ. Sci. Technol. 46, 12467-12475.

Xia, J.G., Nie, L.., Mi, X.M., Wang, W.Z., Ma, YJ., Cao, Z.D., et al. 2015. Behavior, metabolism and swimming physiology in juvenile Spinibarbus sinensis exposed to PFOS under different temperatures. Fish Physiol. Biochem. 41, 1293-1304.

Xie, H.Q., Xu, H.M., Fu, H.L., Hu, Q., Tian, W.J., Pei, X.H., et al., 2013. AhR-mediated effects of dioxin on neuronal acetylcholinesterase expression in vitro. Environ. Health Perspect. 121, 613-618.

Xu, D., Li, C., Wen, Y., Liu, W., 2013. Antioxidant defense system responses and DNA damage of earthworms exposed to perfluorooctane sulfonate (PFOS). Environ. Pollut. 174, 121-127.

Zhang, L., Li, Y.Y., Chen, T., Xia, W., Zhou, Y., Wan, Y.J., et al., 2011. Abnormal development of motor neurons in perfluorooctane sulphonate exposed zebrafish embryos. Ecotoxicology 20, 643-652.

Zhang, L., Niu, J., Wang, Y., Shi, J., Huang, Q., 2014. Chronic effects of PFOA and PFOS on sexual reproduction of freshwater rotifer Brachionus calyciflorus. Chemosphere 114 114-120. 